Gut and Liver, Vol. 12, No. 5, September 2018, pp. 544-554

\title{
Association of Perianal Fistulas with Clinical Features and Prognosis of Crohn's Disease in Korea: Results from the CONNECT Study
}

\author{
Jaeyoung Chun ${ }^{1}$, Jong Pil Im¹, Ji Won Kim², Kook Lae Lee², Chang Hwan Choi ${ }^{3}$, Hyunsoo Kim ${ }^{4}$, Jae Hee Cheon ${ }^{5}$, \\ Byong Duk Ye ${ }^{6}$, Young-Ho Kim ${ }^{7}$, You Sun Kim ${ }^{8}$, Yoon Tae Jeen ${ }^{9}$, Dong Soo Han ${ }^{10}$, Won Ho Kim ${ }^{5}$, and Joo Sung Kim ${ }^{1}$ \\ ${ }^{\prime}$ Department of Internal Medicine and Liver Research Institute, Seoul National University College of Medicine, ${ }^{2}$ Department of Internal \\ Medicine, Seoul Metropolitan Government-Seoul National University Boramae Medical Center, Seoul National University College of Medicine, \\ ${ }^{3}$ Department of Internal Medicine, Chung-Ang University College of Medicine, Seoul, ${ }^{4}$ Department of Internal Medicine, Chonnam National \\ University Medical School, Gwangju, ${ }^{5}$ Department of Internal Medicine, Yonsei University College of Medicine, ${ }^{6}$ Department of Internal \\ Medicine, University of Ulsan College of Medicine, 'Department of Internal Medicine, Sungkyunkwan University School of Medicine, \\ ${ }^{8}$ Department of Internal Medicine, Inje University College of Medicine, ${ }^{9}$ Department of Internal Medicine, Korea University College of Medicine, \\ Seoul, and ${ }^{10}$ Department of Internal Medicine, Hanyang University College of Medicine, Guri, Korea
}

Background/Aims: The disease course and factors associated with poor prognosis in Korean patients with Crohn's disease (CD) have not been fully determined. The aim of this study was to explore potential associations between the clinical characteristics and long-term outcomes of $C D$ and perianal fistulas in a Korean population. Methods: The retrospective Crohn's Disease Clinical Network and Cohort (CONNECT) study enrolled patients diagnosed with CD between July 1982 and December 2008 from 32 hospitals. Those followed for $<12$ months were excluded. Clinical outcomes were CD-related surgery and complications, including nonperianal fistulas, strictures, and intra-abdominal abscesses. Results: The mean follow-up period was 8.77 years (range, 1.0 to 25.8 years). A total of $1,193 \mathrm{CD}$ patients were enrolled, of whom 465 (39.0\%) experienced perianal fistulas. Perianal fistulizing $C D$ was significantly associated with younger age, male gender, $C D$ diagnosed at primary care clinics, and ileocolonic involvement. Both nonperianal fistulas $(p=0.034)$ and intra-abdominal abscesses $(p=0.020)$ were significantly more common in $\mathrm{CD}$ patients with perianal fistulas than in those without perianal fistulas. The rates of complicated strictures and CD-related surgery were similar between the groups. Independently associated factors of nonperianal fistulas were perianal fistulas $(p=0.015)$, female gender $(p=0.048), C D$ diagnosed at referral hospital $(p=0.003)$, and upper gastrointestinal (UGI) involvement $(p=0.001)$. Furthermore, perianal fistulas $(p=0.048)$ and
UGI involvement $(p=0.012)$ were independently associated with the risk of intra-abdominal abscesses. Conclusions: Perianal fistulas predicted the development of nonperianal fistulas and intra-abdominal abscesses in Korean CD patients. Therefore, patients with perianal fistulizing $C D$ should be carefully monitored for complicated fistulas or abscesses.

(Gut Liver 2018;12:544-554)

Key Words: Anal fistula; Crohn disease; Prognosis

\section{INTRODUCTION}

Crohn's disease (CD) is a chronic and relapsing inflammatory disorder characterized by transmural inflammation that occurs in the gastrointestinal tract. ${ }^{1,2}$ It has been recognized as an immune-mediated disease that can results in impaired quality of life and serious complications including fibrotic strictures, intestinal fistulas, and intra-abdominal abscesses. ${ }^{3,4}$ Although the pathogenesis of $\mathrm{CD}$ remains unclear, accumulating evidence suggests that complex interactions between genetic and environmental factors are closely related to the development and perpetuation of intestinal inflammation..$^{5-7}$

Recently, the incidence and prevalence of $\mathrm{CD}$ have been increasing in East Asia. ${ }^{1,8}$ This could be due to environmental changes such as Westernization of diet and lifestyle. ${ }^{9}$ However, the genetic susceptibilities and epidemiological characteristics of $\mathrm{CD}$ in East Asians are thought to differ from those in Cau-

Correspondence to: Ji Won Kim

Department of Internal Medicine, Seoul Metropolitan Government-Seoul National University Boramae Medical Center, Seoul National University College of Medicine, 20 Boramae-ro 5-gil, Dongjak-gu, Seoul 07061, Korea

Tel: +82-2-870-2221, Fax: +82-2-870-3863, E-mail: kjwjor@snu.ac.kr

Received on March 27, 2018. Revised on June 13, 2018. Accepted on June 19, 2018.

pISSN 1976-2283 eISSN 2005-1212 https://doi.org/10.5009/gnl18157

Jaeyoung Chun and Jong Pil Im contributed equally to this work as first authors.

() This is an Open Access article distributed under the terms of the Creative Commons Attribution Non-Commercial License (http://creativecommons.org/licenses/by-nc/4.0) which permits unrestricted non-commercial use, distribution, and reproduction in any medium, provided the original work is properly cited. 
casians. For example, nucleotide-binding oligomerization domain protein 2/caspase recruitment domain protein 15 (NOD2/ CARD15) mutations, which are common genetic variants for susceptibility to CD in Caucasians, ${ }^{10,11}$ are reported to have no association with CD in Korean, ${ }^{12}$ Japanese, ${ }^{13}$ and Chinese populations. ${ }^{14}$ Furthermore, East Asian CD patients have ileocolonic involvement more often than Caucasians. ${ }^{15,16}$ Because of the differences between East Asians and Caucasians in both genotypes and phenotypes of $\mathrm{CD}$, it is important to define the specific clinical characteristics of Korean CD patients in order to select appropriate treatment strategies. However, the disease course and factors associated with poor prognosis for CD in Koreans have not been fully determined.

Perianal fistula is detected in up to $90 \%$ of CD patients with rectal involvement. ${ }^{17}$ Compared to Western countries, the prevalence of perianal complication is likely to be higher in East Asia, ranging from $30.3 \%$ to $58.8 \% .{ }^{17}$ Perianal lesions present with a spectrum of clinical severity from asymptomatic to severe diseases requiring repeated surgical interventions with medical treatment including antibiotics and tumor necrosis factor (TNF)- $\alpha$ antagonists in patients with $\mathrm{CD} \cdot{ }^{18}$ In addition, perianal complications generally denote an aggressive and disabling phenotype of $\mathrm{CD} .{ }^{19}$ However, the relationships between the presence of perianal fistula and the development of CD-related complications including nonperianal fistulas, strictures, or intraabdominal abscesses remain unclear, particularly in East Asians. Thus, the aim of this study was to assess the clinical characteristics and long-term outcomes of CD in terms of potential associations with perianal fistulas in a Korean population.

\section{MATERIALS AND METHODS}

\section{Study population}

The Crohn's Disease Clinical Network and Cohort (CONNECT) study included patients diagnosed with CD between July 1982 and December 2008 from 32 hospitals in Korea. ${ }^{20-24}$ The aims of this retrospective multicenter cohort study were as follows: (1) to determine epidemiological and clinical characteristics by establishing a registered database of CD patients; (2) to establish a genetic research management system for CD patients; (3) to establish a network of patients and of doctors who specialize in the management of $\mathrm{CD}$ in the form of a private nonprofit organization; and (4) to develop Korean-specific diagnostic and therapeutic guidelines for $\mathrm{CD} .^{20}$ All subjects were diagnosed and treated by inflammatory bowel disease (IBD) specialists who were members of the Korean Association for the Study of Intestinal Diseases. CD was diagnosed on the basis of clinical, radiological, endoscopic, and pathological criteria. ${ }^{15,25}$ Patients who were diagnosed with indeterminate colitis, intestinal tuberculosis, or intestinal Behçet's disease were excluded from this cohort. Patients with a follow-up period of $<12$ months or incomplete medical records were also excluded. This study was approved by the institutional review boards at the participating medical centers.

\section{Study protocol}

The medical records of all subjects were reviewed at each participating hospital until May 2014. We evaluated demographic data and clinical characteristics including age at diagnosis, gender, family history of IBD, hospital where patients were diagnosed with $\mathrm{CD}$, exposure to antituberculosis medication, disease location, history of perianal fistulas, medical therapy for $\mathrm{CD}$, and disease-related complications (i.e., nonperianal fistulas, strictures, and intra-abdominal abscess formation) during follow-up of the cohort. Age at diagnosis and disease location were classified according to the revised Montreal classification. ${ }^{26}$ Briefly, age at diagnosis (A1, $\leq 16$ years; A2, 17-40 years; and $\mathrm{A} 3,>40$ years) and location criteria (L1, small bowel; L2, colon; L3, small bowel and colon; and L4, upper gastrointestinal [UGI] tract) were noted. With respect to perianal fistulas, the diagnosis was based on physical examination and endoscopic and/or radiological findings. ${ }^{27}$ The detection time of perianal fistulas was also collected.

Clinical outcomes were CD-related surgery and complications including nonperianal fistulas, strictures, and intra-abdominal abscesses. Nonperianal fistulas (Montreal classification B3) were defined as the development of enteroenteric, enterovesical, or enterocutaneous fistulas. ${ }^{26,28}$ Strictures (Montreal classification B2) were defined as the occurrence of constant luminal narrowing demonstrated by radiological, endoscopic, and/or pathological findings. ${ }^{26,28}$ The detection of strictures required obstructive signs/symptoms or prestenotic dilatation. Intra-abdominal abscesses were defined as extraintestinal fluid collection located in the peritoneal cavity, abdominal wall, or subphrenic region. ${ }^{29}$ Abscess formation located in the anal region was excluded. CDrelated surgery was defined as intestinal resection for medical refractoriness and/or complications of $\mathrm{CD}$ except perianal lesions. Time to the first occurrence of each outcome from diagnosis of $\mathrm{CD}$ was calculated in months.

\section{Statistical analysis}

Statistical analysis was performed with SPSS version 17.0 (SPSS Inc., Chicago, IL, USA). Pearson chi-square test, Fisher exact test, and Student t-test were used, as appropriate, to calculate the statistical significance of the demographic and clinical variables, according to the presence and detection time of perianal fistulas. Rates of clinical outcomes including nonperianal fistulas, strictures, intra-abdominal abscesses and surgery were calculated with actuarial life tables. The KaplanMeier method was used to estimate the cumulative probability of clinical outcomes. Log-rank test was performed to determine the significance of perianal fistulas with respect to difference for each clinical outcome. Multivariable analysis with Cox proportional hazards models was performed to identify independent 
associated factors for nonperianal fistulas and intra-abdominal abscesses. A p-value $<0.05$ was considered statistically significant.

\section{RESULTS}

\section{Baseline demographic and clinical characteristics}

We reviewed the medical records of 1,382 patients who were diagnosed with CD between July 1982 and December 2008 in this cohort. All subjects were ethnically Korean. We excluded 189 of these patients (13.7\%) due to a follow-up duration of $<12$ months (75 patients) or incomplete medical records (114 patients). A total of $1,193 \mathrm{CD}$ patients were finally enrolled in the study (Fig. 1).

The study population comprised 840 men (70.4\%). The mean age at diagnosis of CD was $26.9 \pm 11.9$ years (range, 0 to 77 years). The mean follow-up period was 8.77 years (range, 1.0 to 25.8 years). At the discretion of the physicians, 280 patients (23.5\%) received antituberculosis medication to differentiate intestinal tuberculosis from CD or because of a first impression of intestinal tuberculosis. Thirty patients (2.5\%) had a family history of IBD. With regard to disease location, 733 patients (61.4\%) had ileocolonic involvement at the time of diagnosis of $\mathrm{CD}$. Concomitant UGI disease was detected in 281 patients (23.6\%).

A total of $465 \mathrm{CD}$ patients (39.0\%) experienced perianal fistulas. Among them, perianal fistulas were detected before and after diagnosis of CD in 318 (68.4\%) and 147 patients (31.6\%), respectively. Among the 147 patients with perianal fistulas which were detected after diagnosis of $\mathrm{CD}$, perianal fistulas were diagnosed after the occurrence of CD-related surgery and complications including nonperianal fistulas, strictures, and intra-abdominal abscesses in $15(10.2 \%)$ and 11 patients (7.5\%), respectively. Perianal fistulas were significantly associated with younger age at diagnosis $(\mathrm{p}<0.001)$, male gender $(\mathrm{p}=0.043)$, diagnosis of $\mathrm{CD}$ at primary care clinics $(\mathrm{p}<0.001)$, and ileocolonic involvement $(\mathrm{p}<0.001)$ (Table 1). Patients with perianal fistulas after diagnosis of CD showed a female predominance $(\mathrm{p}<0.001)$ and a higher proportion of CD diagnosed at referral hospital $(p=0.012)$ compared to those with perianal fistulas before diagnosis of CD (Supplementary Table 1).

\section{Treatment and clinical outcomes of CD according to the presence of perianal fistulas}

During the follow-up period, 748 patients (62.7\%) received systemic corticosteroids for the treatment of CD. Azathioprine and 6-mercaptopurine were administered to 880 patients (73.8\%), and TNF- $\alpha$ antagonists including infliximab and adalimumab were prescribed to 336 patients (28.2\%). Rates of administration of 5-aminosalicylic acid (5-ASA), antibiotics, systemic corticosteroids, azathioprine/6-mercaptopurine, and TNF- $\alpha$ antagonist (infliximab) for the treatment of CD were significantly higher in patients with perianal fistulas than in those without perianal fistulas (Table 2). Moreover, patients who experienced perianal fistulas after diagnosis of CD showed significantly higher rates of antibiotics, topical corticosteroids, methotrexate, and TNF- $\alpha$ antagonist treatment compared to those with perianal fistulas before diagnosis of CD (Supplementary Table 2).

Nonperianal fistulas were found in 192 patients (16.1\%) during the follow-up period. The median time to complicated nonperianal fistulas was 20 months (range, 0 to 202 months) from diagnosis of $\mathrm{CD}$. Cumulative rates of nonperianal fistulas at 5, 10, and 15 years were $11.1 \%, 19.5 \%$, and 22.3\%, respectively (Fig. 2A). Stricture complications occurred in 338 patients (28.3\%), and the median time to complicated strictures was 10 months (range, 0 to 273 months) from diagnosis of $\mathrm{CD}$. $\mathrm{Cu}$ mulative rates of complicated strictures at 5, 10, and 15 years were $21.2 \%, 32.1 \%$, and 38.4\%, respectively (Fig. 2B). Intraabdominal abscesses were detected in 163 patients (13.7\%), and the median time to intra-abdominal abscess formation was 21

1,382 Patients diagnosed with CD between 1982 and 2008

in a Korean retrospective cohort enrolled from 32 hospitals were included

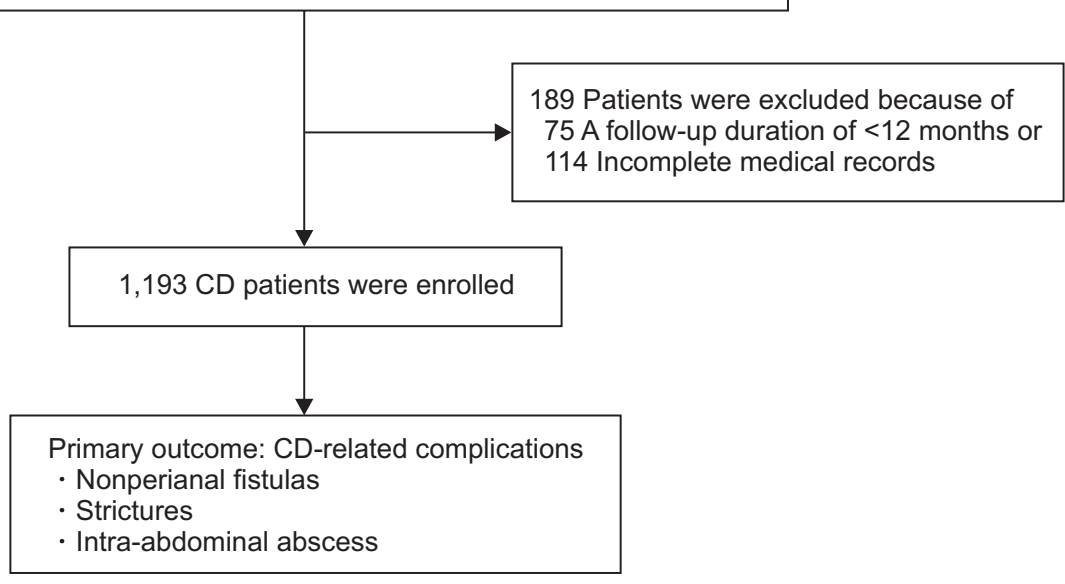

Fig. 1. Flowchart for patient selection. $\mathrm{CD}$, Crohn's disease. 
Table 1. Baseline Characteristics

\begin{tabular}{|c|c|c|c|}
\hline Characteristics & $\begin{array}{c}\text { Without } \\
\text { perianal fistulas }\end{array}$ & $\begin{array}{c}\text { With } \\
\text { perianal fistulas }\end{array}$ & p-value \\
\hline No. of patients & $728(61.0)$ & $465(39.0)$ & - \\
\hline Age at diagnosis, yr & $29.0 \pm 13.3$ & $23.6 \pm 8.4$ & $<0.001$ \\
\hline Age at diagnosis (Montreal classification)* & & & $<0.001$ \\
\hline$\leq 16$ yr (A1) & $76(10.4)$ & 69 (14.8) & \\
\hline $17-40$ yr (A2) & $521(71.6)$ & $377(81.1)$ & \\
\hline$\geq 41$ yr (A3) & $131(18.0)$ & $19(4.1)$ & \\
\hline Male sex & $497(68.3)$ & $343(73.8)$ & 0.043 \\
\hline Hospital where patients were diagnosed with CD & & & $<0.001$ \\
\hline Primary care clinic & $111(15.4)$ & $131(28.3)$ & \\
\hline Referral hospital & $602(83.7)$ & $332(71.7)$ & \\
\hline Overseas & $6(0.8)$ & 0 & \\
\hline Anti-tuberculosis medication & $171(23.7)$ & $109(23.6)$ & 0.985 \\
\hline Family history of IBD & $16(2.3)$ & $14(3.1)$ & 0.382 \\
\hline Location of disease (Montreal classification)* & & & $<0.001$ \\
\hline Ileum (L1) & $203(27.9)$ & $73(15.7)$ & \\
\hline Colon (L2) & $107(14.7)$ & 68 (14.6) & \\
\hline Ileocolon (L3) & 409 (56.2) & $324(69.7)$ & \\
\hline Concomitant UGI disease (L4) & $185(25.4)$ & $96(20.6)$ & 0.058 \\
\hline
\end{tabular}

Data are presented as number $(\%)$ or mean \pm SD.

$\mathrm{CD}$, Crohn's disease; IBD, inflammatory bowel disease; UGI, upper gastrointestinal.

${ }^{*}$ Age at diagnosis and disease location was determined according to the revised Montreal classification.

Table 2. Perianal Fistulas and Treatment for Crohn's Disease

\begin{tabular}{lccr}
\hline & $\begin{array}{c}\text { Without } \\
\text { perianal fistulas } \\
(\mathrm{n}=728)\end{array}$ & $\begin{array}{c}\text { With } \\
\text { perianal fistulas } \\
(\mathrm{n}=465)\end{array}$ & $\mathrm{p}$-value \\
\hline 5-ASA & $691(97.3)$ & $451(99.1)$ & 0.031 \\
Antibiotics & $364(52.4)$ & $327(72.7)$ & $<0.001$ \\
Topical & $99(13.8)$ & $63(13.9)$ & 0.980 \\
$\quad$ corticosteroids & & & \\
Systemic & $436(60.3)$ & $312(68.1)$ & 0.007 \\
$\quad$ corticosteroids & & & \\
Azathioprine/ & $502(69.0)$ & $378(81.3)$ & $<0.001$ \\
$\quad$ 6-mercaptopurine & & & \\
Methotrexate & $12(1.7)$ & $9(1.9)$ & 0.713 \\
TNF- $\alpha$ antagonist & $179(24.6)$ & $157(33.8)$ & 0.001 \\
$\quad$ Infliximab & $155(21.3)$ & $145(31.2)$ & $<0.001$ \\
$\quad$ Adalimumab & $48(6.6)$ & $28(6.0)$ & 0.693 \\
\hline
\end{tabular}

Data are presented as number (\%).

5-ASA, 5-aminosalicylic acid; TNF- $\alpha$, tumor necrosis factor- $\alpha$.

months (range, 0 to 218 months) from diagnosis of $\mathrm{CD}$. Cumulative rates of intra-abdominal abscess at 5, 10, and 15 years were 10.0\%, 14.7\%, and 20.2\%, respectively (Fig. 2C). During the follow-up, 324 patients (27.2\%) with CD underwent surgery for refractory disease and/or complications. The median time to surgery was 4 months (range, 0 to 193 months) from diagnosis of $\mathrm{CD}$. Cumulative rates of surgery at 5,10 , and 15 years were 21.7\%, 30.3\%, and 38.5\%, respectively (Fig. 2D).

The clinical outcomes of CD according to the presence of perianal fistulas are shown in Table 3 and Fig. 3. Complicated nonperianal fistulas were significantly more common in patients with perianal fistulizing CD (18.9\%) than in those without perianal fistulizing CD (14.3\%) $(\mathrm{p}=0.034)$. Cumulative rates of nonperianal fistulas in patients with versus without perianal fistulizing CD were 12.7\% versus 10.0\%, 21.9\% versus $17.8 \%$, and $30.0 \%$ versus $23.9 \%$ at 5,10 , and 20 years, respectively (Fig. 3A). Furthermore, intra-abdominal abscess was detected more frequently in CD patients with perianal fistulas (16.6\%) compared to those who had not experienced perianal fistulas (11.8\%) $(p=0.020)$. Cumulative rates of intra-abdominal abscess in patients with versus without perianal fistulizing CD were $11.2 \%$ versus $9.3 \%, 17.8 \%$ versus $12.4 \%$, and $29.3 \%$ versus $21.8 \%$ at 5 , 10, and 20 years, respectively (Fig. 3B). However, no significant difference was found in complicated strictures between CD patients with (30.1\%) and without perianal fistulas (27.2\%) $(\mathrm{p}=0.564)$. Cumulative rates of complicated strictures in patients with versus without perianal fistulizing $\mathrm{CD}$ were $22.3 \%$ versus $20.5 \%, 32.6 \%$ versus $31.8 \%$, and $44.2 \%$ versus $49.8 \%$ at 5,10 , and 20 years, respectively (Fig. 3C). There was no significant difference in surgical rates between the two groups $(p=0.202)$. 
A
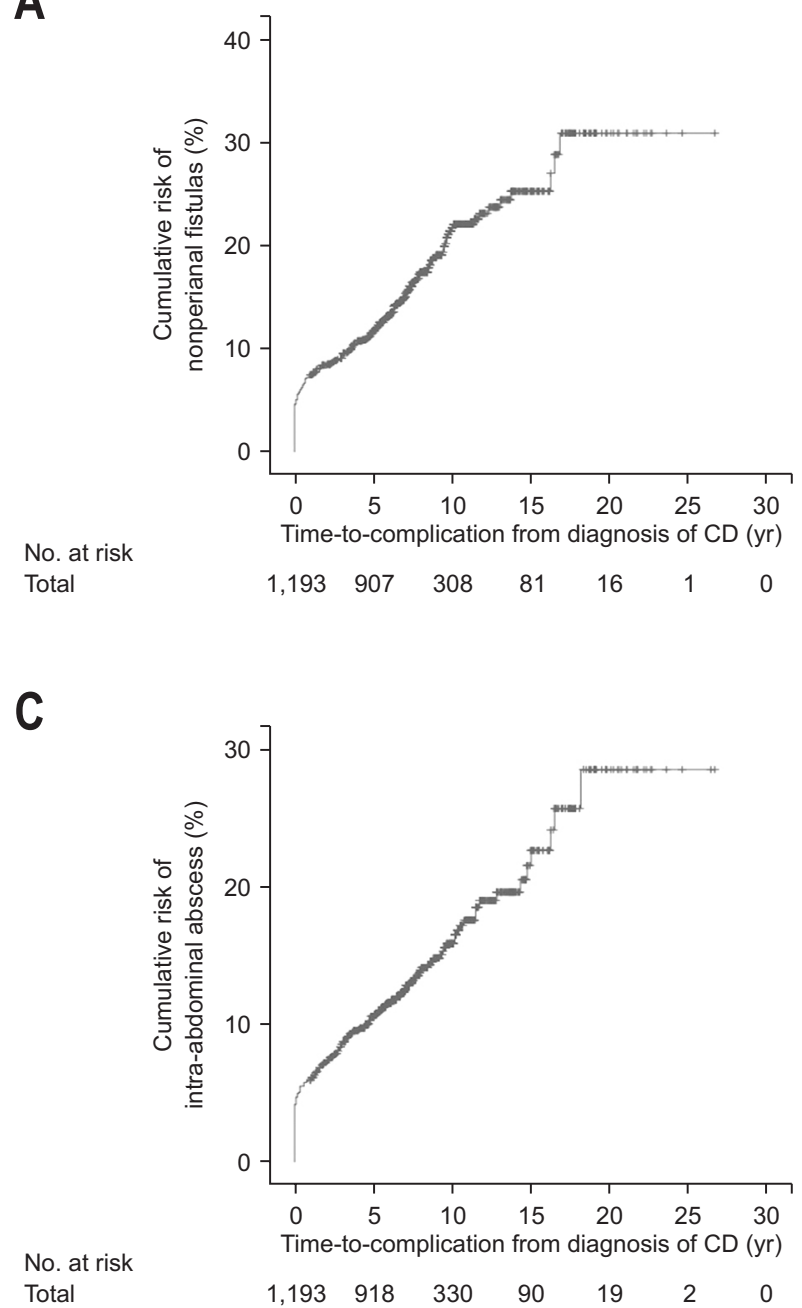
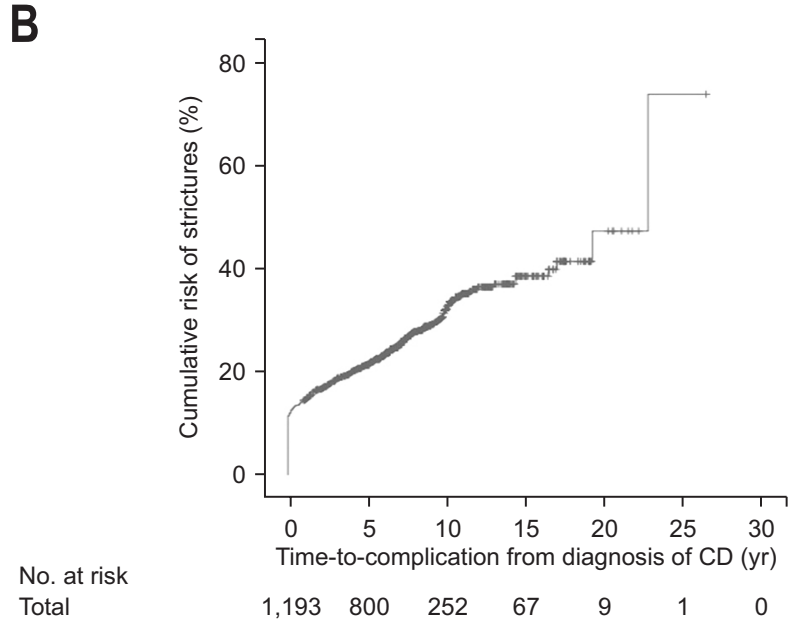

No. at risk

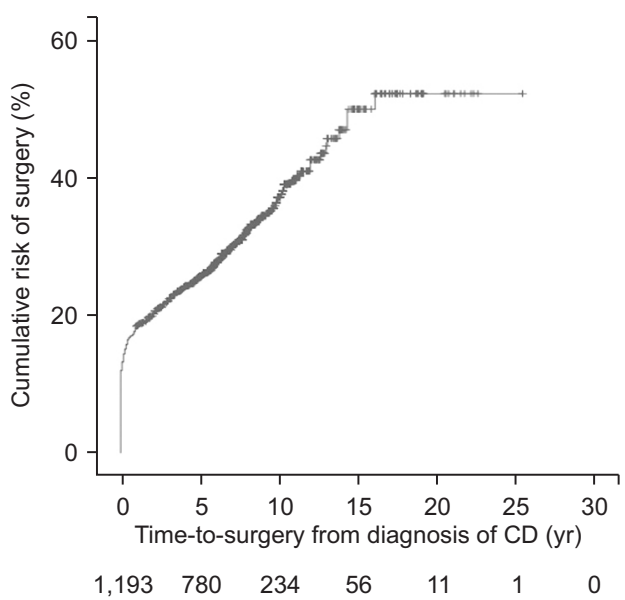

Fig. 2. Kaplan-Meier curves for clinical outcomes of Crohn's disease (CD). (A) Cumulative risks of complicated nonperianal fistulas, (B) intraabdominal abscess formation, (C) complicated strictures, and (D) CD-related surgery.

Table 3. Perianal Fistulas and Clinical Outcomes of Crohn's Disease

\begin{tabular}{lcrr}
\hline & \multicolumn{2}{c}{ Without } & \multicolumn{2}{c}{ With } & \\
& $\begin{array}{c}\text { perianal fistulas } \\
(\mathrm{n}=728)\end{array}$ & $\begin{array}{c}\text { perianal fistulas } \\
(\mathrm{n}=465)\end{array}$ & p-value \\
\hline CD-related complications & & & \\
$\quad$ Nonperianal fistulas & $104(14.3)$ & $88(18.9)$ & 0.034 \\
Strictures & $198(27.2)$ & $140(30.1)$ & 0.564 \\
Intra-abdominal & $86(11.8)$ & $77(16.6)$ & 0.020 \\
$\quad$ & & & \\
abscess & $202(27.7)$ & $122(26.2)$ & 0.202 \\
CD-related surgery & & &
\end{tabular}

Data are presented as number (\%).

$\mathrm{CD}$, Crohn's disease.

Cumulative rates of surgery in patients with versus without perianal fistulizing CD were 20.7\% versus 22.5\%, 29.1\% versus $30.9 \%$, and $36.1 \%$ versus $40.5 \%$ at 5, 10, and 15 years, respectively (Fig. 3D).

In terms of detection time of perianal fistulas, patients with perianal fistulas after diagnosis of $\mathrm{CD}$ underwent surgery related to $\mathrm{CD}$ more frequently, compared to those with perianal fistulas before diagnosis of $\mathrm{CD}(\mathrm{p}=0.050)$. However, no significant differences in CD-related complications between the two groups were found (Supplementary Table 3 and Supplementary Fig. 1).

\section{Associated factors of nonperianal fistulas and intra- abdominal abscesses}

Univariable analysis revealed that associated factors of complicated nonperianal fistulas were female gender $(p=0.046)$, ileocolonic involvement ( $\mathrm{p}=0.011)$, concomitant UGI involvement ( $p=0.001)$, and perianal fistulas $(p=0.034)$. Multivariable analysis indicated that independent associated factors of nonperianal fistulas were perianal fistulas (adjusted hazard ratio [HR], 1.430; 95\% confidence interval [CI], 1.072 to $1.908 ; \mathrm{p}=0.015$ ), female gender (adjusted HR, 1.341; 95\% CI, 1.003 to 1.793; p=0.048), diagnosis of $\mathrm{CD}$ at a referral hospital (adjusted HR, 1.852; 95\% CI, 1.227 to 2.796; $\mathrm{p}=0.003$ ), and concomitant UGI involvement (adjusted HR, 1.655; 95\% CI, 1.222 to 2.241, p=0.001) (Table 4). 

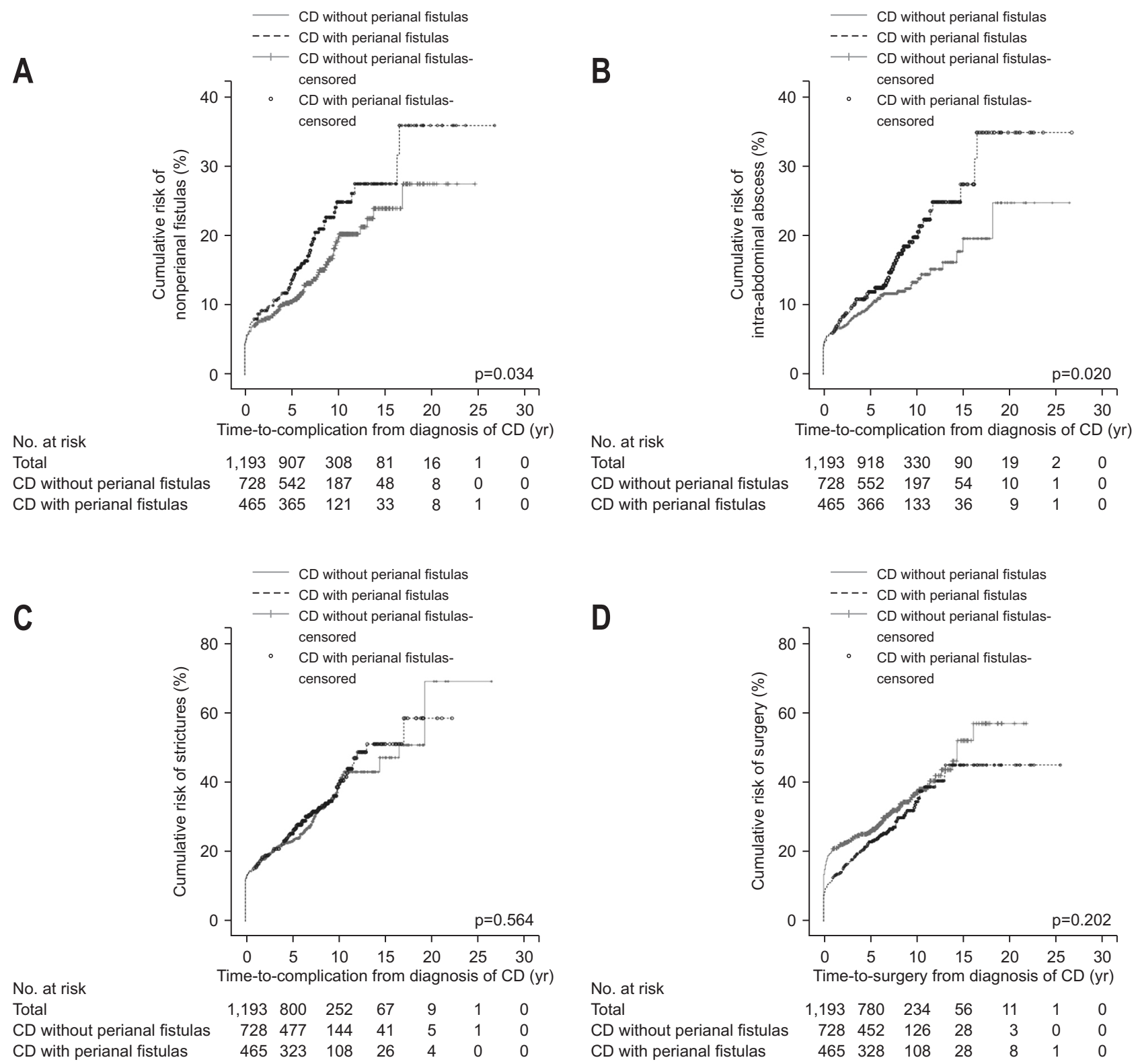

Fig. 3. Kaplan-Meier curves for clinical outcomes of Crohn's disease (CD) according to the presence of perianal fistula. (A) Cumulative risks of complicated nonperianal fistulas, (B) intra-abdominal abscess formation, (C) complicated strictures, and (D) CD-related surgery.

Univariable analysis revealed that associated factors of intraabdominal abscess formation were 17 to 40 years of age (Montreal classification $\mathrm{A} 2, \mathrm{p}=0.020$ ), concomitant UGI involvement ( $p=0.028)$, and perianal fistulas $(\mathrm{p}=0.020)$. Multivariable analysis showed that perianal fistulas (adjusted HR, 1.292; 95\% CI, 1.005 to $1.748, \mathrm{p}=0.048$ ) and concomitant UGI involvement (adjusted $\mathrm{HR}, 1.510$; 95\% CI, 1.094 to 2.082; $\mathrm{p}=0.012$ ) were independently associated with the risk of intra-abdominal abscesses. (Table 5).

\section{DISCUSSION}

In this large multicenter cohort study, patients with perianal fistulizing CD were more likely to have experienced complications of nonperianal fistulas and intra-abdominal abscesses, but not strictures, than those without perianal fistulizing $\mathrm{CD}$. To the best of our knowledge, this study was the first to investigate the relationships between perianal fistulizing $\mathrm{CD}$ and these diseaserelated complications in an Asian population. Our results are comparable with those of a population-based cohort study from Canada in which CD patients with perianal fistulas were at a 5-fold increased risk of nonperianal fistulas compared to those who had not had perianal fistulas. ${ }^{30}$ In a multicenter study in the United States and Europe, there was also a significant association between perianal disease and intestinal fistulas, espe- 
Table 4. Predictors of Nonperianal Fistula in the Study Population

\begin{tabular}{|c|c|c|c|c|c|}
\hline \multirow{2}{*}{ Variable } & \multicolumn{2}{|c|}{$\begin{array}{l}\text { Univariate analysis } \\
\text { (log-rank test) }\end{array}$} & \multicolumn{3}{|c|}{$\begin{array}{c}\text { Multivariate analysis } \\
\text { (Cox proportional hazard models) }\end{array}$} \\
\hline & $\%$ & p-value & Adjusted HR & $95 \% \mathrm{CI}$ & p-value \\
\hline Age at diagnosis (Montreal classification)* & & 0.271 & - & - & - \\
\hline$\leq 16$ yr (A1) & 17.2 & & & & \\
\hline $17-40$ yr (A2) & 16.8 & & & & \\
\hline$\geq 41 \mathrm{yr}(\mathrm{A} 3)$ & 10.7 & & & & \\
\hline Sex & & 0.046 & & & \\
\hline Male & 14.4 & & 1 (reference) & & \\
\hline Female & 20.1 & & 1.341 & $1.003-1.793$ & 0.048 \\
\hline Hospital where patients were diagnosed with CD & & 0.068 & & & \\
\hline Primary care clinic & 11.2 & & 1 (reference) & & \\
\hline Referral hospital & 17.3 & & 1.852 & $1.227-2.796$ & 0.003 \\
\hline Overseas & 16.7 & & 4.393 & $0.214-19.027$ & 0.489 \\
\hline Anti-tuberculosis medication & & 0.927 & - & - & - \\
\hline No & 15.7 & & & & \\
\hline Yes & 17.1 & & & & \\
\hline Family history of IBD & & 0.169 & - & - & - \\
\hline No & 16.4 & & & & \\
\hline Yes & 6.7 & & & & \\
\hline Location of disease (Montreal classification)* & & 0.011 & & & \\
\hline Ileum (L1) & 14.1 & & 1 (reference) & & \\
\hline Colon (L2) & 8.6 & & 0.627 & $0.353-1.113$ & 0.111 \\
\hline Ileocolon (L3) & 18.7 & & 1.263 & $0.887-1.798$ & 0.195 \\
\hline Concomitant UGI disease (L4) & & 0.001 & & & \\
\hline No & 14.0 & & 1 (reference) & & \\
\hline Yes & 22.7 & & 1.655 & $1.222-2.241$ & 0.001 \\
\hline Perianal fistula & & 0.034 & & & \\
\hline No & 14.3 & & 1 (reference) & & \\
\hline Yes & 18.9 & & 1.430 & $1.072-1.908$ & 0.015 \\
\hline
\end{tabular}

HR, hazard ratio; CI, confidence interval; CD, Crohn's disease; IBD, inflammatory bowel disease; UGI, upper gastrointestinal.

*Age at diagnosis and disease location was determined according to the revised Montreal classification.

cially in CD patients with colonic disease. ${ }^{31}$ These findings suggest that perianal fistulas are highly associated with nonperianal fistulas in CD patients regardless of ethnicity, although perianal and nonperianal fistulas might represent distinct phenotypes with different behaviors. ${ }^{30}$ In addition, perianal fistulizing CD was associated with the development of intra-abdominal abscess in the disease course, a finding that is consistent with the significant relationship between perianal and nonperianal fistulas found in this study.

We also found that the presence of perianal fistulas was an independent associated factor of the complications including nonperianal fistula and intra-abdominal abscess. To date, a few cohort studies have reported independent associated factors for CD-related complications including nonperianal fistulas, strictures, and intra-abdominal abscesses in Western countries. In a single-center cohort study in France, anoperineal disease was a significant risk factor for fistulizing complications. ${ }^{32}$ By contrast, a population-based cohort study in the United States ${ }^{33}$ showed that perianal disease at diagnosis of CD was not an independent risk factor for developing either stricturing or penetrating complications. However, this study did not investigate whether perianal disease could predict nonperianal fistulas alone in the study population. Considering the relationship between perianal and nonperianal fistulas reported by previous studies, ${ }^{30,31}$ the presence of perianal fistulas may be a good clinical indicator of complicated nonperianal fistulas and/or intra-abdominal abscesses in $\mathrm{CD}$ patients.

Some previous reports have demonstrated that perianal fistulizing $\mathrm{CD}$ is a risk factor for poor clinical outcome. In a multicenter randomized controlled trial of patients with active 
Table 5. Predictors of Intra-abdominal Abscess in the Study Population

\begin{tabular}{|c|c|c|c|c|c|}
\hline \multirow[t]{2}{*}{ Variable } & \multicolumn{2}{|c|}{$\begin{array}{l}\text { Univariate analysis } \\
\text { (log-rank test) }\end{array}$} & \multicolumn{3}{|c|}{$\begin{array}{c}\text { Multivariate analysis } \\
\text { (Cox proportional hazard models) }\end{array}$} \\
\hline & $\%$ & p-value & Adjusted HR & $95 \% \mathrm{CI}$ & p-value \\
\hline Age at diagnosis (Montreal classification)* & & 0.020 & & & \\
\hline$\leq 16$ yr (A1) & 9.0 & & 1 (reference) & & \\
\hline $17-40$ yr (A2) & 15.4 & & 1.816 & $0.989-3.643$ & 0.076 \\
\hline$\geq 41$ yr (A3) & 8.0 & & 1.153 & $0.544-2.444$ & 0.710 \\
\hline Sex & & 0.338 & - & - & - \\
\hline Male & 14.0 & & & & \\
\hline Female & 12.7 & & & & \\
\hline Hospital where patients were diagnosed with $\mathrm{CD}$ & & 0.236 & - & - & - \\
\hline Primary care clinic & 10.7 & & & & \\
\hline Referral hospital & 14.0 & & & & \\
\hline Overseas & 33.3 & & & & \\
\hline Anti-tuberculosis medication & & 0.807 & - & - & - \\
\hline No & 13.4 & & & & \\
\hline Yes & 14.3 & & & & \\
\hline Family history of IBD & & 0.097 & - & - & -- \\
\hline No & 13.9 & & & & \\
\hline Yes & 3.3 & & & & \\
\hline Location of disease (Montreal classification)* & & 0.099 & - & - & - \\
\hline Ileum (L1) & 12.7 & & & & \\
\hline Colon (L2) & 8.6 & & & & \\
\hline Ileocolon (L3) & 15.1 & & & & \\
\hline Concomitant UGI disease (L4) & & 0.028 & & & \\
\hline No & 12.4 & & 1 (reference) & & \\
\hline Yes & 17.8 & & 1.510 & $1.094-2.082$ & 0.012 \\
\hline Perianal Fistula & & 0.020 & & & \\
\hline No & 11.8 & & 1 (reference) & & \\
\hline Yes & 16.6 & & 1.292 & $1.005-1.748$ & 0.048 \\
\hline
\end{tabular}

$\mathrm{HR}$, hazard ratio; CI, confidence interval; CD, Crohn's disease; IBD, inflammatory bowel disease; UGI, upper gastrointestinal.

*Age at diagnosis and disease location was determined according to the revised Montreal classification.

$\mathrm{CD}$, perianal disease increased the risk of resistance to corticosteroids. ${ }^{34}$ Beaugerie et $a l .^{35}$ showed that perianal disease at initial presentation of $\mathrm{CD}$ was associated with disabling clinical course related to corticosteroid dependence, hospitalization, and surgical intestinal resection for disease flares. In a retrospective study, patients with perianal fistulizing CD had a 1.7-fold increased risk of surgery compared to those who had not had perianal fistulizing $\mathrm{CD} .{ }^{36}$ Moreover, a recent study reported that patients with perianal $\mathrm{CD}$ had a higher risk of reoperation after primary bowel resection related to $\mathrm{CD}$ compared to those without perianal $\mathrm{CD} .^{37}$ However, in this observational cohort study, presentation of perianal fistulas in CD was not associated with the risk of CD-related surgery. $\mathrm{CD}$ patients who required surgery for free perforation experienced less intra-abdominal abscess, perianal and intestinal fistulas, but were significantly associated with bowel strictures in a retrospective study of results from the CONNECT. ${ }^{24}$ Taken together, it remains unclear whether perianal fistulas are the indicator of bowel resection in patients with $\mathrm{CD}$. However, patients with perianal fistulizing $\mathrm{CD}$ also required more frequent corticosteroids, immunomodulators, and TNF- $\alpha$ antagonists for the treatment of $\mathrm{CD}$ than those without perianal fistulizing $\mathrm{CD}$, suggesting that perianal fistulizing $\mathrm{CD}$ is likely to be a severe relapsing disease during follow-up. Therefore, patients with perianal fistulizing CD should be carefully monitored for the development of disabling complications including nonperianal fistulas and intra-abdominal abscesses. In addition, early treatment with TNF- $\alpha$ antagonists can be considered to prevent complications and reduce surgical requirements in patients with perianal fistulizing $\mathrm{CD}$, as well as those in Western countries. $^{38}$ 
In terms of detection time of perianal fistulas, patients with perianal fistulas after $\mathrm{CD}$ diagnosis required intestinal resection for medical refractoriness and/or complications of CD except perianal lesions more frequently, compared to presentation of perianal fistulas before diagnosis of $\mathrm{CD}$ regardless of $\mathrm{CD}$-related complications. In this study, the patients who experienced perianal fistulas following diagnosis of $\mathrm{CD}$ also required more intensive medical treatment including antibiotics, methotrexate and TNF- $\alpha$ antagonist for treatment of active CD than those with perianal fistulas before diagnosis of $\mathrm{CD}$. It remains unclear how the detection time of perianal fistulas affects the clinical course of disease in $\mathrm{CD}$, but the presentation of perianal fistulas after diagnosis of $\mathrm{CD}$ might be an indicator of disease activity and aggressive clinical course.

The cumulative frequency of perianal fistulizing $\mathrm{CD}$ at referral centers has been reported to range from 13\% to 38\% in Western countries. ${ }^{39}$ In the present multicenter cohort study, the prevalence of perianal fistulas in Korean patients with $\mathrm{CD}$ was 39\% at referral hospitals. A previous hospital-based study at a tertiary care center in Korea showed that the prevalence of perianal fistulas was $46.8 \%{ }^{40}$ Thus, perianal fistulas may occur more frequently in Korean patients with $\mathrm{CD}$ than in patients with CD from Western countries. However, the high prevalence of perianal fistulas found by previous studies in Korea might have been due to referrals to tertiary care centers, because the presence of perianal fistulas requires a multidisciplinary approach for management of $\mathrm{CD}$. This level of care is available at tertiary care centers rather than primary care clinics. Further population-based studies are needed to determine whether Korean patients with $\mathrm{CD}$ show a higher prevalence of perianal fistulas compared to Caucasians.

In this study, perianal fistulas were significantly more common in CD patients of younger age, male gender, and ileocolonic involvement and in those who were diagnosed at primary care clinics. Patients who are younger when first diagnosed with CD appear to be at the greatest risk of perianal fistulas. ${ }^{19}$ In previous reports, age $<40$ years at diagnosis was a risk factor for fistulizing disease including perianal fistulas. ${ }^{30,32}$

Some previous studies have reported that male patients with $\mathrm{CD}$ are more likely to have perianal fistulas compared to female patients with $\mathrm{CD},{ }^{41,42}$ however, there was no significant gender difference with respect to the presence of perianal fistulas in a population-based study. ${ }^{43}$ Male gender might be a possible risk factor for perianal fistulizing $\mathrm{CD}$ in spite of the conflicting results reported thus far. With respect to the location of disease, earlier studies in Western countries have reported that patients with isolated ileal CD are at the lowest risk of perianal fistulas. ${ }^{19}$ The negative association between perianal fistulas and isolated ileal disease was also found in the present study. However, perianal fistulas occurred most often in patients with ileocolonic disease in our cohort, in contrast to previous studies in Western countries, which reported that CD patients with active rectal dis- ease are most likely to develop perianal fistulas. ${ }^{19}$ In accordance with the results of previous studies, ${ }^{40,44}$ the Korean population in this study was more likely to have ileocolonic CD compared to Caucasians, especially in those with perianal fistulas. Interestingly, both male predominance and more ileocolonic involvement is the epidemiologic characteristics of Korean CD patients compared to Western countries. ${ }^{45}$ It may be associated with the high prevalence of perianal fistulas in Korean.

The frequency of perianal fistulas was relatively high in patients who were diagnosed with $\mathrm{CD}$ at primary care clinics compared to those diagnosed at referral hospitals. The reasons for this observation remain unclear, but possible explanations include both the large proportion (68\%) of perianal fistulas that were detected before diagnosis of $\mathrm{CD}$ and the high degree of suspicion of $\mathrm{CD}$ among primary care physicians managing young patients who present with perianal fistulas in Korea. Some of the patients who present with perianal fistulas might prefer primary care clinics specialized for coloproctology in which surgeons work, although the information on the specialty of primary care clinics was not available in this study.

We also observed that concomitant UGI involvement was an independent associated factor for both complicated nonperianal fistulas and/or intra-abdominal abscesses in patients with CD. In accordance with our results, Tang et al. ${ }^{30}$ reported that fistulizing CD including perianal fistulas was associated with a predisposition to UGI disease in Canadian patients. Moreover, UGI involvement was significantly associated with the time to first major abdominal surgery in a population-based cohort study from the United States. ${ }^{46}$ These findings suggest that UGI involvement is also a marker for poor clinical outcomes, especially penetrating complications, in patients with $\mathrm{CD}$ regardless of ethnicity.

This multicenter cohort study has several limitations. First, further information regarding the characteristics of perianal fistulas including type, activity, treatment, and outcomes of lesion was not available because of its retrospective nature. Second, a variety of confounding factors including smoking, clinical disease activity, and biological markers such as C-reactive protein ${ }^{47}$ could not be controlled for due to a lack of medical records. Finally, this was a hospital-based cohort study that included patients from 32 referral hospitals. Thus, it may be biased toward more severe disease compared to population-based studies and may overestimate disease-related complications in a Korean population.

In conclusion, the presence of perianal fistulas was associated with the development of nonperianal fistulas and intra-abdominal abscesses in Korean patients with CD. Therefore, patients with perianal fistulizing $\mathrm{CD}$ should be carefully monitored for complicated nonperianal fistulas and intra-abdominal abscesses. 


\section{CONFLICTS OF INTEREST}

No potential conflict of interest relevant to this article was reported.

\section{ACKNOWLEDGEMENTS}

This work was supported by the research program funded by the Korea Centers for Disease Control and Prevention (2016E63001-02).

\section{REFERENCES}

1. Kim ES, Kim WH. Inflammatory bowel disease in Korea: epidemiological, genomic, clinical, and therapeutic characteristics. Gut Liver 2010;4:1-14.

2. Yoo S, Jung YS, Park JH, et al. Fatigue severity and factors associated with high fatigue levels in Korean patients with inflammatory bowel disease. Gut Liver 2014;8:148-153.

3. Lee SH, Kwon JE, Cho ML. Immunological pathogenesis of inflammatory bowel disease. Intest Res 2018;16:26-42.

4. Kim YS, Jung SA, Lee KM, et al. Impact of inflammatory bowel disease on daily life: an online survey by the Korean Association for the Study of Intestinal Diseases. Intest Res 2017;15:338-344.

5. Abraham C, Cho JH. Inflammatory bowel disease. N Engl J Med 2009;361:2066-2078.

6. Knights D, Lassen KG, Xavier RJ. Advances in inflammatory bowel disease pathogenesis: linking host genetics and the microbiome. Gut 2013;62:1505-1510

7. Nagao-Kitamoto H, Kitamoto S, Kuffa P, Kamada N. Pathogenic role of the gut microbiota in gastrointestinal diseases. Intest Res 2016;14:127-138.

8. Chang CW, Wong JM, Tung CC, Shih IL, Wang HY, Wei SC. Intestinal stricture in Crohn's disease. Intest Res 2015;13:19-26.

9. Thia KT, Loftus EV Jr, Sandborn WJ, Yang SK. An update on the epidemiology of inflammatory bowel disease in Asia. Am J Gastroenterol 2008;103:3167-3182.

10. Hugot JP, Chamaillard M, Zouali H, et al. Association of NOD2 leucine-rich repeat variants with susceptibility to Crohn's disease. Nature 2001;411:599-603.

11. Ogura $\mathrm{Y}$, Bonen DK, Inohara N, et al. A frameshift mutation in NOD2 associated with susceptibility to Crohn's disease. Nature 2001;411:603-606.

12. Croucher PJ, Mascheretti S, Hampe J, et al. Haplotype structure and association to Crohn's disease of CARD15 mutations in two ethnically divergent populations. Eur J Hum Genet 2003;11:6-16.

13. Inoue N, Tamura K, Kinouchi Y, et al. Lack of common NOD2 variants in Japanese patients with Crohn's disease. Gastroenterology 2002;123:86-91.

14. Guo QS, Xia B, Jiang Y, Qu Y, Li J. NOD2 3020insC frameshift mutation is not associated with inflammatory bowel disease in Chinese patients of Han nationality. World J Gastroenterol
2004;10:1069-1071.

15. Yang SK, Yun S, Kim JH, et al. Epidemiology of inflammatory bowel disease in the Songpa-Kangdong district, Seoul, Korea, 1986-2005: a KASID study. Inflamm Bowel Dis 2008;14:542-549.

16. Oriuchi T, Hiwatashi N, Kinouchi Y, et al. Clinical course and longterm prognosis of Japanese patients with Crohn's disease: predictive factors, rates of operation, and mortality. J Gastroenterol 2003;38:942-953.

17. Im JP. Adalimumab or infliximab: which is better for perianal fistula in Crohn's disease? Intest Res 2017;15:147-148.

18. Yoon JY, Cheon JH, Park SJ, Kim TI, Kim WH. Effects of perianal involvement on clinical outcomes in Crohn's disease over 10 years. Gut Liver 2018;12:297-305.

19. Ingle SB, Loftus EV Jr. The natural history of perianal Crohn's disease. Dig Liver Dis 2007;39:963-969.

20. Cheon JH, Kim YS, Ye BD, et al. Crohn's Disease Clinical Network and Cohort (CONNECT) study: the first step toward nationwide multicenter research of Crohn's disease in Korea. Intest Res 2014;12:173-175.

21. Jung YS, Park DI, Ye BD, et al. Long-term clinical outcomes of urban versus rural environment in Korean patients with Crohn's disease: results from the CONNECT study. J Crohns Colitis 2015;9:246-251.

22. Moon CM, Jung SA, Kim SE, et al. Clinical factors and disease course related to diagnostic delay in Korean Crohn's disease patients: results from the CONNECT Study. PLoS One 2015;10:e0144390.

23. Kim B, Cheon JH, Moon HJ, et al. Crohn's disease prognosis and early immunomodulator therapy: Results from the CONNECT study. J Gastroenterol Hepatol 2016;31:126-132.

24. Doh YS, Kim YS, Bae SI, et al. The clinical characteristics of patients with free perforation in Korean Crohn's disease: results from the CONNECT study. BMC Gastroenterol 2015;15:31.

25. Kim NH, Jung YS, Moon CM, et al. Long-term clinical outcomes of korean patient with Crohn's disease following early use of infliximab. Intest Res 2014;12:281-286.

26. Satsangi J, Silverberg MS, Vermeire S, Colombel JF. The Montreal classification of inflammatory bowel disease: controversies, consensus, and implications. Gut 2006;55:749-753.

27. Kamm MA, Ng SC. Perianal fistulizing Crohn's disease: a call to action. Clin Gastroenterol Hepatol 2008;6:7-10.

28. Henckaerts L, Van Steen K, Verstreken I, et al. Genetic risk profiling and prediction of disease course in Crohn's disease patients. Clin Gastroenterol Hepatol 2009;7:972-980.e2.

29. Yoneno K, Hisamatsu T, Matsuoka K, et al. Risk and management of intra-abdominal abscess in Crohn's disease treated with infliximab. Digestion 2014;89:201-208.

30. Tang LY, Rawsthorne P, Bernstein CN. Are perineal and luminal fistulas associated in Crohn's disease? A population-based study. Clin Gastroenterol Hepatol 2006;4:1130-1134.

31. Sachar DB, Bodian CA, Goldstein ES, et al. Is perianal Crohn's disease associated with intestinal fistulization? Am J Gastroenterol 


$$
\text { 2005;100:1547-1549. }
$$

32. Cosnes J, Cattan S, Blain A, et al. Long-term evolution of disease behavior of Crohn's disease. Inflamm Bowel Dis 2002;8:244-250.

33. Thia KT, Sandborn WJ, Harmsen WS, Zinsmeister AR, Loftus EV Jr. Risk factors associated with progression to intestinal complications of Crohn's disease in a population-based cohort. Gastroenterology 2010;139:1147-1155.

34. Gelbmann CM, Rogler G, Gross V, et al. Prior bowel resections, perianal disease, and a high initial Crohn's disease activity index are associated with corticosteroid resistance in active Crohn's disease. Am J Gastroenterol 2002;97:1438-1445.

35. Beaugerie L, Seksik P, Nion-Larmurier I, Gendre JP, Cosnes J. Predictors of Crohn's disease. Gastroenterology 2006;130:650-656.

36. Lapidus A, Bernell 0, Hellers G, Löfberg R. Clinical course of colorectal Crohn's disease: a 35-year follow-up study of 507 patients. Gastroenterology 1998;114:1151-1160.

37. Han YM, Kim JW, Koh SJ, et al. Patients with perianal Crohn's disease have poor disease outcomes after primary bowel resection. J Gastroenterol Hepatol 2016;31:1436-1442.

38. Kim JW. Results of the first survey for the current status of inflammatory bowel disease management in Asian countries. Intest Res 2016;14:199-201.

39. American Gastroenterological Association Clinical Practice Committee. American Gastroenterological Association medical position statement: perianal Crohn's disease. Gastroenterology
2003;125:1503-1507.

40. Ye BD, Yang SK, Cho YK, et al. Clinical features and long-term prognosis of Crohn's disease in Korea. Scand J Gastroenterol 2010;45:1178-1185.

41. Hellers G, Bergstrand 0, Ewerth S, Holmström B. Occurrence and outcome after primary treatment of anal fistulae in Crohn's disease. Gut 1980;21:525-527.

42. Lapidus A. Crohn's disease in Stockholm County during 19902001: an epidemiological update. World J Gastroenterol 2006;12:75-81.

43. Schwartz DA, Loftus EV Jr, Tremaine WJ, et al. The natural history of fistulizing Crohn's disease in Olmsted County, Minnesota. Gastroenterology 2002;122:875-880.

44. Moon CM, Park DI, Kim ER, et al. Clinical features and predictors of clinical outcomes in Korean patients with Crohn's disease: a Korean association for the study of intestinal diseases multicenter study. J Gastroenterol Hepatol 2014;29:74-82.

45. Ng WK, Wong SH, Ng SC. Changing epidemiological trends of inflammatory bowel disease in Asia. Intest Res 2016;14:111-119.

46. Zallot C, Peyrin-Biroulet L. Clinical risk factors for complicated disease: how reliable are they? Dig Dis 2012;30 Suppl 3:67-72.

47. Yang DH, Yang SK, Park SH, et al. Usefulness of C-reactive protein as a disease activity marker in Crohn's disease according to the location of disease. Gut Liver 2015;9:80-86. 